Article

\title{
Assessing the Heat Vulnerability of Different Local Climate Zones in the Old Areas of a Chinese Megacity
}

\author{
Zhi Cai ${ }^{1}{ }^{1}$, Yan Tang ${ }^{1, *}$, Kai Chen ${ }^{2}$ and Guifeng Han ${ }^{3}$ \\ 1 School of Architecture, Tsinghua University, Beijing 100084, China; czhi911@foxmail.com \\ 2 CAUPD Beijing Planning \& Design Consultants Co., China Academy of Urban Planning and Design, Beijing \\ 100044, China; lockepark@126.com \\ 3 College of Architecture and Urban Planning, Chongqing University, Chongqing 400045, China; \\ hangf@cqu.edu.cn \\ * Correspondence: yantang@mail.tsinghua.edu.cn
}

Received: 28 February 2019; Accepted: 2 April 2019; Published: 5 April 2019

check for updates

\begin{abstract}
Frequent and extreme heat waves have strongly influenced the sustainable development of cities and resulted in a higher level of mortality in residents. Using the Local Climate Zone (LCZ) classification scheme, combined with the factors of land surface temperature (LST), building age (BA), and housing price (HP), and the normalized values of which represent heat exposure, sensitivity, and adaptability, respectively, this paper investigates a practical method for assessing the heat vulnerability of different LCZ classes in the old areas of a Chinese megacity, taking the Yuzhong district of Chongqing city as a case study. The results reveal that the distribution of LCZ classes in this study area exhibits a typical circle-layer distribution pattern from the city center to the suburbs. Heavy industry areas are the most vulnerable, with the highest exposure to heat waves, the oldest building age and the lowest housing price. Compact class areas (compact high-rise, compact mid-rise and compact low-rise) are usually more vulnerable than open class areas (open high-rise, open mid-rise, and open low-rise) and low-rise buildings are always more susceptible to heat waves than mid-rise and high-rise buildings. The methods and findings can help us to better understand the comprehensive and space-time action rules of heat vulnerability, thereby inspiring scientific and rational urban planning strategies to mitigate or adapt to urban heat weaves towards the sustainable development of cities and society.
\end{abstract}

Keywords: heat vulnerability; old areas; local climate zone; assessment; urban spatial form

\section{Introduction}

Global climate change has strongly influenced the development of sustainable cities and society and increased the intensity of extreme heat waves. Heat waves in urban areas not only encourage greater water and electricity consumption, resulting in a shortage of hydropower resources [1], and aggravating urban air pollution [2], but also have a significant negative impact on residents' health [3]. Heat waves can significantly reduce the frequency of fitness activities, walking, and other outdoor activities [4], thereby increasing the risk of diseases, such as obesity, cardiovascular diseases and diabetes [5,6]. The Centers for Disease Control and Prevention (CDC) of the United States noted that the risk of symptoms, such as asphyxia, fatigue and cramps, increased significantly after frequent exposure to extremely high temperatures [7]. High temperatures affect one's cognitive abilities and lead to a decline in learning and thinking abilities [8], in addition to being conducive to the spread and outbreak of diseases [9,10], resulting in higher mortality rates in people who live in hotter areas [11]. For example, Rovers (2014) [12] pointed out that the number of deaths caused by heat waves in the Netherlands increased by eight people per degree, when the temperatures exceeded $20^{\circ} \mathrm{C}$. In 2003 , 
an extreme heat wave caused more than 70,000 deaths in Europe [13], and the extreme heat waves in the United States from 1999 to 2010 resulted in 7415 deaths, more than the total number of deaths from typhoons, floods, earthquakes and other disasters during the same period [14].

Therefore, it is urgent to assess the vulnerability of areas subject to urban heat waves and provide corresponding mitigation or adaptation strategies based on it. This has become a hot topic in the study of healthy cities. Heat vulnerability refers to the degree of vulnerability or inability of urban residents to cope with the adverse effects of heat waves, and it is typically composed of three types of indicators: exposure, sensitivity and adaptability $[15,16]$. In this context, "exposure" refers to the proximity of the location of a group or individual to the hazards of heat waves, which reflect the characteristics, intensity and frequency of the heat waves suffered by urban residents [17]. The most widely used indicators for evaluating heat exposure include the urban thermal environment (e.g., air temperature, land surface temperature and urban heat island intensity) $[18,19]$ and urban spatial parameters (e.g., sky view factor and impervious surface fraction) [20]. In this context, "sensitivity" refers to the degree to which urban residents change their physiological structure in the face of the external interference of extreme heat waves. Widely used evaluation indicators include the proportion of vulnerable groups, such as the elderly, infants and patients with diseases [19], and some studies also incorporate household income and gender into the sensitivity evaluation index system [21]. In this context, "adaptability" refers to the ability of urban residents to respond to heat wave disasters and recover from disaster losses [17,22]. The most widely used indicators include the proportion of air conditioning used in buildings and the accessibility of residents to medical facilities or parks [19,21,23].

We can find that heat vulnerability indicators have multiple aspects, such as the physical environment and socio-economics conditions [17,22]. However, most previous studies just used an "administrative unit" (e.g., district, sub-district, or community), as a spatial scale in the heat vulnerability assessment, and attempted to discover the vulnerability of each administrative unit in the city $[24,25]$. It is noteworthy that every unit is composed of many factors (e.g., buildings, green space and blue space) and different urban spatial forms (e.g., high-rise and low-rise buildings), all of which show a great difference in their spatial distribution as well as land utilization and have a great impact on the heat vulnerability assessment results. Without knowing which factors or forms have the greatest impact on urban heat vulnerability, it is difficult to directly apply the assessment results to guide the environment improvement of each administrative unit through sustainable urban planning and design approaches. Therefore, it is useful to divide the entire urban space into various units, based on the form and factor features of certain areas, and use these units, instead of administrative units, as the spatial scale for heat vulnerability assessments and related calculations, since the result would be very beneficial in formulating more targeted planning and design strategies to improve the urban environment and reduce heat risks.

Fortunately, the Local Climate Zone (LCZ) classification scheme, proposed by Stewart and Oke (2012) [26], creates such a bridge, linking the built environment, urban spatial form with climate research. Using a unified urban morphological index system in a regular spatial scale, the LCZ scheme identified the urban spatial form in 10 built-up classes (LCZ 1-10) and seven land cover classes (LCZ A-G) (Table A1), where built-up classes are composed of constructed features on a pre-dominant land cover, land cover classes are dominant by nature features (e.g., trees, water bodies), seasonal or ephemeral properties (e.g., snow-covered ground, dry/wet ground). The LCZ scheme can clearly illustrate the distribution of different land use/cover and urban morphology, and with a high resolution it is easy to determine the thermal effect of urban spatial form and find its difference in each LCZ class [27-29]. Thus, the LCZ scheme has gradually attracted the attention of urban environmental and climate researchers worldwide [30-33]. While LCZ classification is still being improved, most existing studies focus on the "thermal environment" and pay little attention to the "heat vulnerability" caused by different human groups and the differences in heat resistance and adaptability between them, which greatly limits the application of the LCZ scheme. Thus, it is of great value to combine LCZ research with the urban heat vulnerability assessment and calculate the heat vulnerability of different 
LCZ classes in a city, which will not only enrich the dimension of LCZ research, but also expand the application fields of heat vulnerability. Therefore, to explore a new quantitative method to assess the heat vulnerability and reveal the correlation rules between LCZ classes and heat risk, this paper takes the Yuzhong district of Chongqing city, China, as an example to assess the heat vulnerabilities of various LCZ classes in old areas of a typical Chinese megacity. It aims to discover:

(1) what the typical distribution rules of LCZ classes in the old areas of the Chinese megacity are;

(2) how to assess urban heat vulnerabilities based on LCZ classification;

(3) what the relationship between LCZ classes and heat vulnerability indicators is; and

(4) what the distribution rule of the heat vulnerabilities in the old areas, according to LCZ classes, is.

\section{Materials and Methods}

\subsection{Study Area}

Chongqing Yuzhong district is located in Southwestern China, between $29^{\circ} 31^{\prime} 50^{\prime \prime}-29^{\circ} 34^{\prime} 20^{\prime \prime}$ north latitude and $106^{\circ} 28^{\prime} 50^{\prime \prime}-106^{\circ} 35^{\prime} 10^{\prime \prime}$ east longitude. It belongs to a subtropical monsoon climate. According to the data of local meteorological stations, the annual average temperature of Yuzhong district is $17.6^{\circ} \mathrm{C}$, the extreme minimum temperature is $-1.8^{\circ} \mathrm{C}$, the maximum temperature can reach $42.2{ }^{\circ} \mathrm{C}$ and the number of high-temperature days (above $35^{\circ} \mathrm{C}$ ) in summer can reach $15-25$ days [34]. The land area of Yuzhong district is $18.54 \mathrm{~km}^{2}$, the elevation ranges from 167.2 to $389.1 \mathrm{~m}$, the local permanent population is 689,000 , and the floating population is 294,000 (Statistical Yearbook of Yuzhong District, 2014). The population density reaches $53,000 / \mathrm{km}^{2}$. The dense population combined with the surrounding mountainous terrain and intersecting rivers (Figure 1a), intensifies the city's annual average humidity (above 70\%) and significant urban heat island effect. On the other hand, Yuzhong district, as the birthplace of Chongqing City, has been fully urbanized and has entered a stage of renewal and transformation, confronted by the typical problems as other old areas of Chinese mega-cities, such as an ageing population, uneven distribution of infrastructure and spatial differentiation of the population associated with various socio-economic factors.

\subsection{Data Source and Processing}

\subsubsection{Date Source and Preprocessing}

Cloud free Landsat 8 remote sensing images, acquired at 11:27 a.m. (local time) on 10 July 2016, were used to retrieve the Land Surface Temperature (LST), which is the hottest day in summer, and the images (path 128, row 39) were downloaded from the website (www.giscloud.cn). Before retrieval, the images were preprocessed using ENVI software (version 5.1), performing such processes as geometric correction, study area clipping and radiation correction. Other data, such as building information (e.g., age, area and floor), demographics, terrain and land use, came from the local urban and rural planning bureau and civil affairs bureau. The data on building prices came from a housing transaction website (https://cq.lianjia.com/ershoufang/yuzhong/). All of the preprocessed data were imported to a GIS database, using QGIS software (version 2.18.27) for spatial analysis and zonal statistics. SPSS software (version 25) was used to analyze the Pearson correlations between some indicators.

\subsubsection{Identifying Spatial Scale}

Many studies pointed out that there is a spatial parameter correlation between urban morphology factors and LST [35-38], which is based on a grid scale, and their correlation is more significant at approximately $250 \mathrm{~m}$ in this study area. To avoid ambiguity and ensure the standard classification of LCZ classes, a $250 \times 250 \mathrm{~m}$ grid size was selected as the spatial scale in this study. 

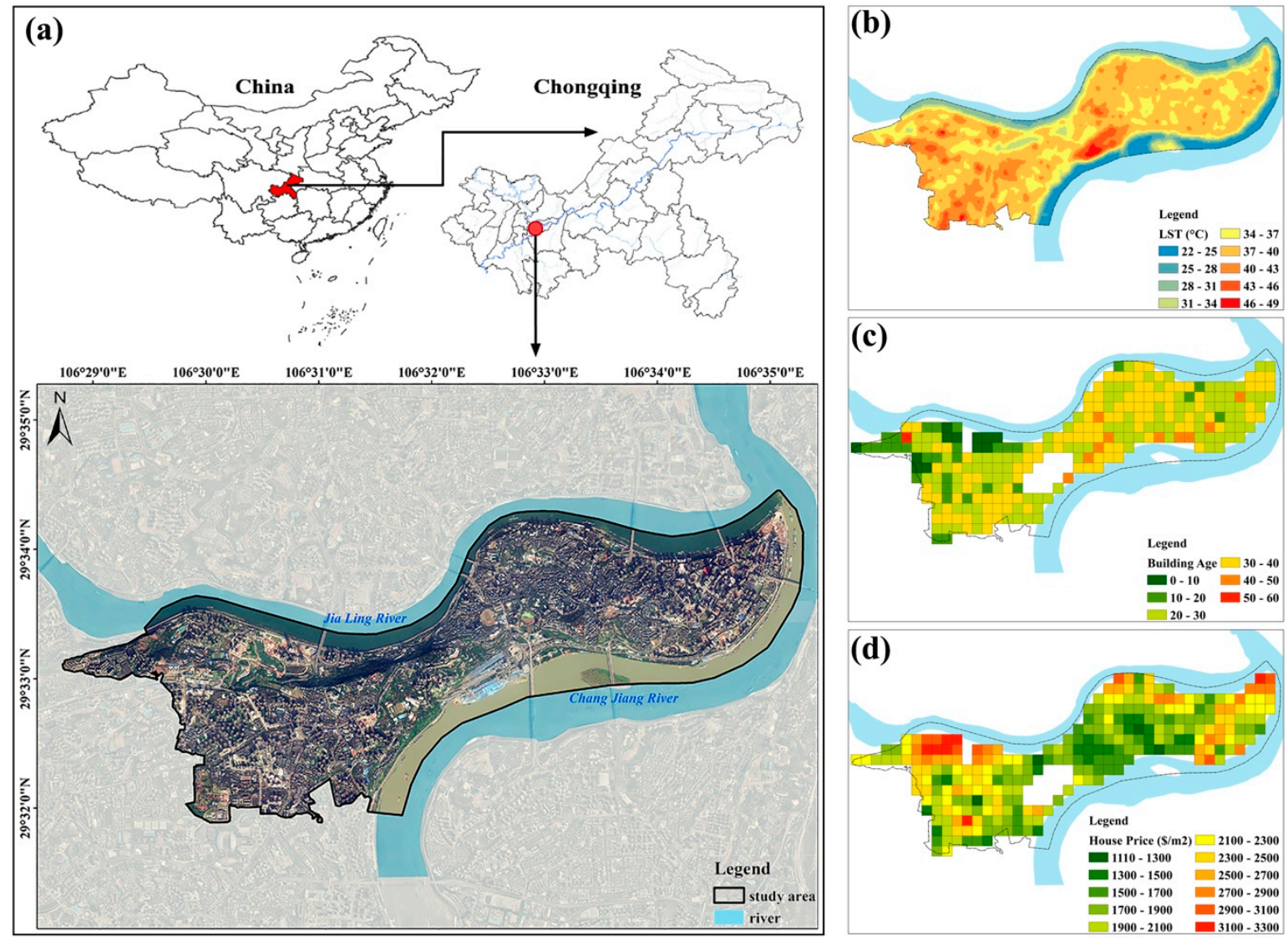

Figure 1. (a) Location and study area; (b) distribution of land surface temperature; (c) distribution of building age at a $250 \mathrm{~m}$ grid scale; (d) distribution of housing price $\left(\$ / \mathrm{m}^{2}\right)$ at a $250 \mathrm{~m}$ grid scale.

\subsubsection{Identifying Heat Vulnerability Indicators}

To explore the easily acquired data to assess the urban heat vulnerability, which is particularly suitable for Chinese mega-cities, this paper introduces three factors for modeling rapidly developing areas: LST, building age (BA) and housing price (HP), which represent heat exposure, heat sensitivity and heat adaptability, respectively. To ensure the uniform units of different factors, all of the data were normalized within a range of $0-1$.

\section{Exposure}

Heat waves are significantly related to health [9-11], whereas the distribution of LST and air temperature are highly consistent [39-42]. Therefore, this paper uses LST to evaluate the heat exposure; the higher the LST, the higher the heat exposure. LST was retrieved using the atmospheric correction method in the Landsat 8 Thermal Infrared Sensor (TIRS) band (band 10) and normalized the vegetation index (NDVI), which was extracted in the red band (R, band 4) and near-infrared band (NIR, band 5), the process and formulas of which are based on the work of Cai (2018) [43]. The retrieved LST $\left(22-49^{\circ} \mathrm{C}\right)$ (Figure $1 \mathrm{~b})$ is highly consistent with the air temperature $\left(28-38^{\circ} \mathrm{C}\right)$ of the same day, implying that the retrieved results are reliable. The LST normalization formula is as follows:

$$
\mathrm{LST}_{\text {nor }}=\left(\mathrm{x}-\mathrm{LST}_{\min }\right) /\left(\mathrm{LST}_{\max }-\mathrm{LST}_{\text {min }}\right)
$$

\section{Sensitivity}

Many studies have pointed out that there is a significant positive correlation between BA and the proportion of vulnerable groups (e.g., elderly and low-income) in the older areas of the megacity [44,45]. We found identical results in this study area, where the correlation between the mean BA and the 
proportion of elderly people at the community level is $0.473^{* *}(p<0.001)$, that is, there are more elderly people living in old communities with older housing. Furthermore, the lack of infrastructure maintenance and fewer medical facilities in old communities make these areas more vulnerable to heat waves, and poor ventilation conditions with lower cooling efficiencies in old buildings worsen the situation [46]. Thus, BA is used as an indicator to represent heat sensitivity, that is, the older the building, the higher the heat sensitivity. The BA normalization formula is as follows:

$$
\mathrm{BA}_{\text {nor }}=\left(\mathrm{x}-\mathrm{BA}_{\min }\right) /\left(\mathrm{BA}_{\max }-\mathrm{BA}_{\min }\right)
$$

Adaptability

Housing price can better reflect the socio-economic conditions of occupants; those who live in more expensive housing can be assumed to have more air conditioning and medical expenses [47], and therefore more adaptability to heat waves. Thus, this paper uses HP as an index to evaluate heat adaptability, that is, the higher the HP, the higher the heat adaptability. The HP normalization is as follows:

$$
\mathrm{HP}_{\text {nor }}=\left(\mathrm{x}-\mathrm{HP}_{\min }\right) /\left(\mathrm{HP}_{\max }-\mathrm{HP}_{\min }\right)
$$

\subsubsection{Land Cover Classification}

The maximum likelihood of the supervised classification method in the ENVI software was used to classify the land cover based on Landsat 8 remote sensing data, and 100 regions of interest (ROI) were extracted to train the samples before classification, after which the Kappa index reached 0.86 . Finally, the land cover was classified into five categories: green space, water bodies, bare land, paved surfaces, and impervious surfaces.

\subsubsection{LCZ Classification}

The LCZ classification scheme identified the urban area as 17 classes, 10 of which were built-up and seven that were land cover $[26,48]$, and 10 standard urban morphological factors' values, such as sky view factor (SVF), impervious surface fraction, surface albedo and height of roughness elements, were provided for classification (Table A1). Referencing related studies [29,49], some factors have a higher correlation with each other, such as SVF and aspect ratio. Thus, only four key factors (SVF, building surface fraction, impervious surface fraction and height of roughness elements) were used as parameters to classify LCZ in this study, whereas urban morphological factors are calculated using the Urban Multi-scale Environmental Predictor (UMEP) plug-in in the QGIS software (version 2.18.27).

\subsection{Assessment Method}

In terms of the assessment methods on heat vulnerability, there are many existing heat vulnerability assessment methods, such as the overlay method and cluster analysis based on GIS spatial analysis [19,50], the equal weight method [51,52], principal component analysis [53], multi-criteria decision analysis [54] and multiplication method [25]. The equal weight method is simple to use and easily popularizes and realizes multi-site evaluation and comparison. In a scenario where it is unclear which index is important or which are equally important, the equal weight method can ensure the transparency and adjustability of the quantitative assessment process. The equal weight method formula for assessing the heat venerability of LCZ classes is as follows:

$$
\mathrm{HVI}=\mathrm{LST}_{\text {nor }}+\mathrm{BA}_{\text {nor }}-\mathrm{HP}_{\text {nor }}
$$

where HVI is the heat vulnerability index, $\mathrm{LST}_{\text {nor }}$ refers to the normalized land surface temperature, $\mathrm{BA}_{n o r}$ is the normalized building age and $\mathrm{HP}_{n o r}$ stands for the normalized housing price.

In summary, the entire working process of this study has three steps (Figure 2). 
Step 1: Divide the study area into $250 \times 250 \mathrm{~m}$ grid series and calculate the urban morphology factors and other indicators; then, classify every grid into LCZ classes according to their given values, as shown in Table A1.

Step 2: Resample the LST and zonal mean values of the building age and housing price $\left(\$ / \mathrm{m}^{2}\right)$ at a $250 \mathrm{~m}$ spatial resolution; then, analyze the distribution of LST, BA, and HP, and their correlations using the LCZ classes.

Step 3: Normalize the three indicators that represent heat exposure $\left(\mathrm{LST}_{\text {nor }}\right)$, sensitivity $\left(\mathrm{BA}_{\text {nor }}\right)$ and adaptability $\left(\mathrm{HP}_{\text {nor }}\right)$ and use the equal weight method to assess the heat vulnerability; then, analyze the relationship between the LCZ classes and heat vulnerability index.

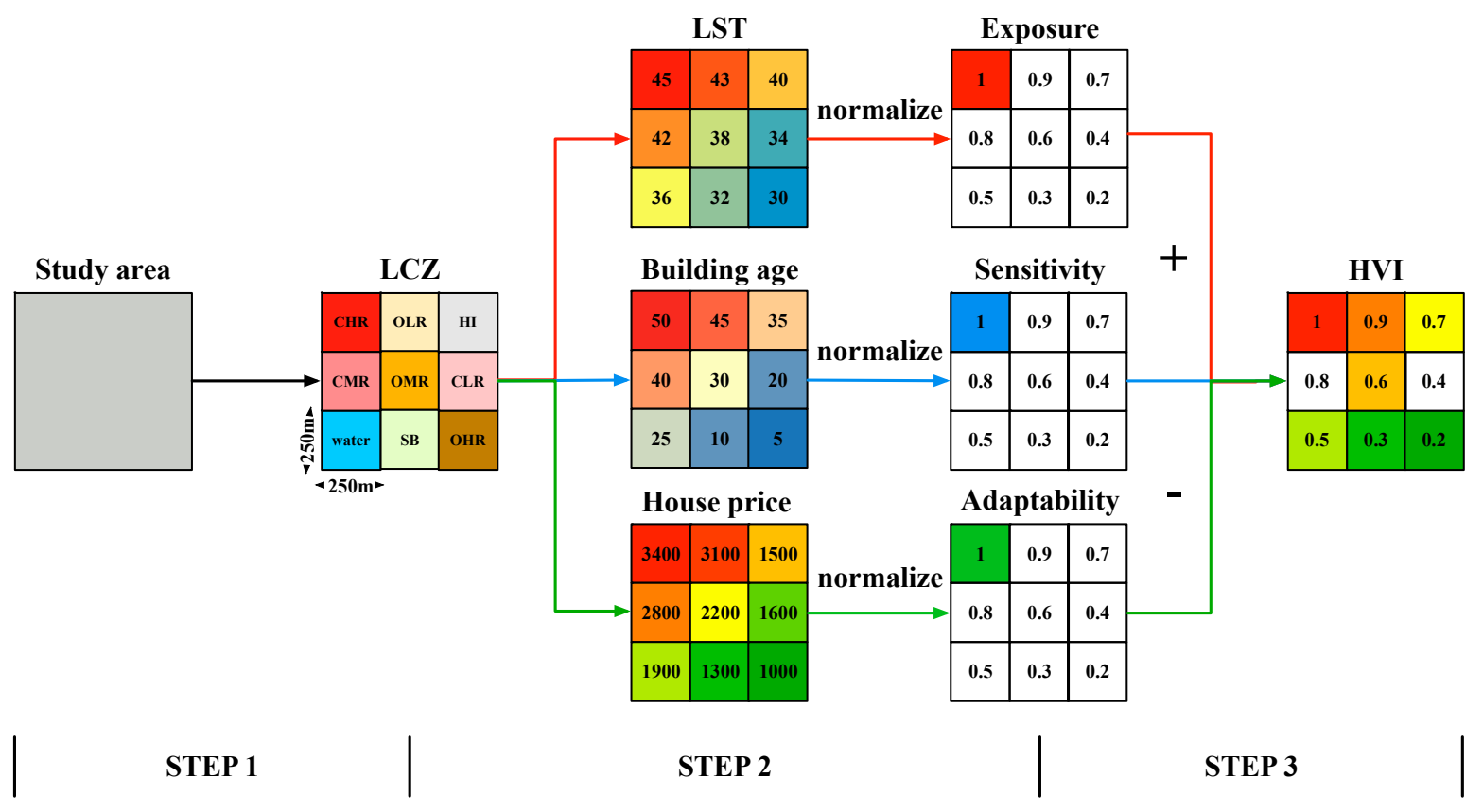

Figure 2. Three steps of the heat vulnerability assessment process.

\section{Results}

\subsection{Distribution of Local Climate Zone Classes}

The study area is classified into $13 \mathrm{LCZ}$ classifications, exhibiting a typical circle-layer distribution pattern (Figure 3b). That is, the LCZ classes are distributed as compact classes in the city center and as open classes in the suburbs and are surrounded by water bodies. Figure 3 shows that compact mid-rise (CMR) and compact low-rise (CLR) buildings are predominantly located in the eastern part of the study area, and sparsely built (SB) and open high-rise (OHR) buildings are primarily located in the western part of the study area. Site 1 is the core area of the city center, which has always been a priority area for development and centralized construction. After years of rapid development, the contradiction between rapid economic development and a shortage of land resources has recently become more prominent. Simultaneously, the burgeoning market economy pushes the original mountain landscape continuously encroached by high-intensity construction. The area's urban spatial form exhibits a radiating trend, from compact high-rise (CHR) to CMR and CLR. Site 2 is the new urban development area that is primarily characterized by residential functions, where construction is always difficult due to large fluctuations of terrain; thus, SB classes are distributed in the area with a larger slope, while the gentle slope area and the area near water bodies are predominated by OHR classes.

There are no buildings existing and no people living in the area where it identified as land cover classes (e.g., water bodies, paved, and trees). Therefore, those LCZ classes are excluded in the 
comprehensive assessment of heat vulnerability, since most of the assessment factors are based on building and population characters.

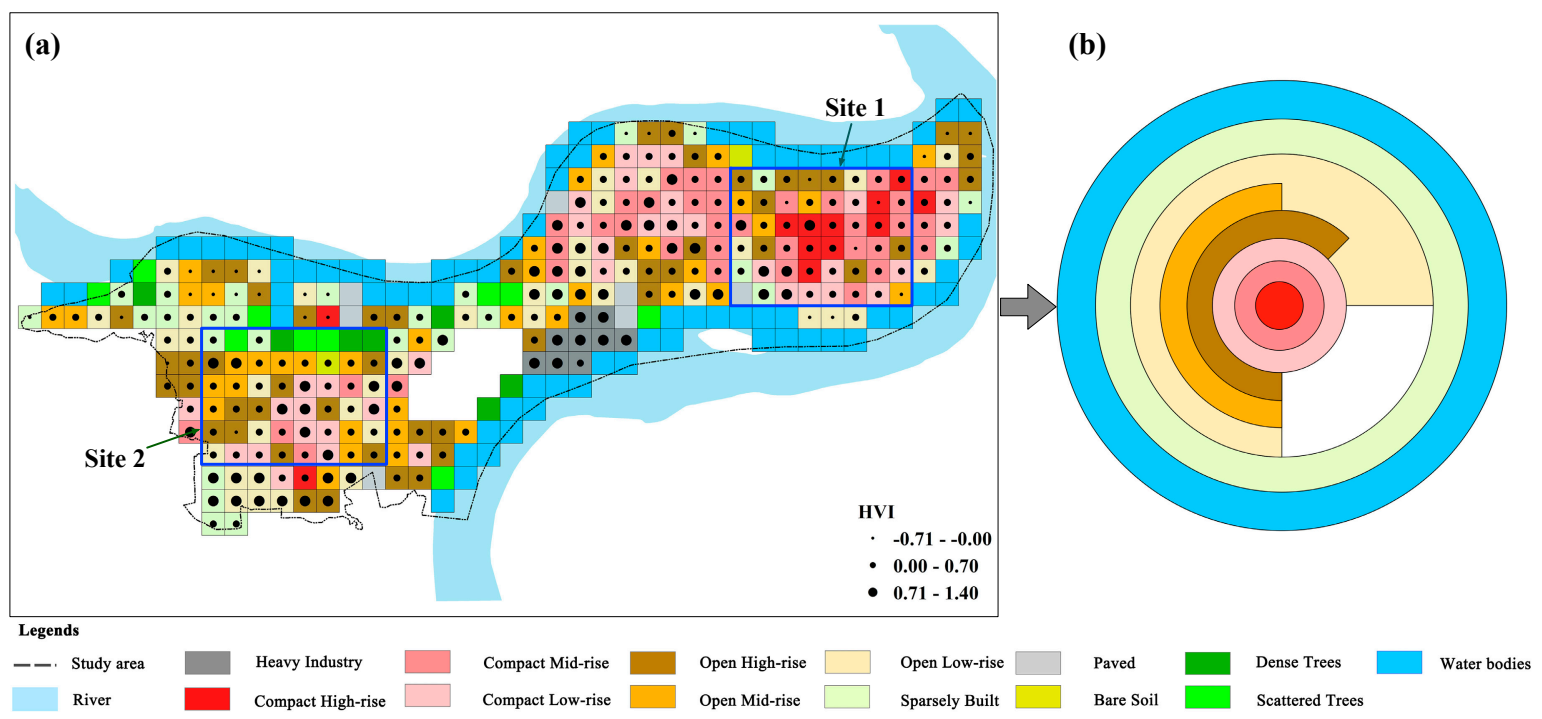

Figure 3. Distribution of Local Climate Zone (LCZ) classes (a) and a typical circle-layer distribution pattern of the study area $(\mathbf{b})$.

\subsection{Land Surface Temperature of LCZ Classes}

The mean LST among different LCZ classes are as follows (in descending order): heavy industry (HI) $\left(41.96{ }^{\circ} \mathrm{C}\right), \mathrm{CLR}\left(39.20^{\circ} \mathrm{C}\right), \mathrm{OLR}\left(38.94^{\circ} \mathrm{C}\right), \mathrm{CMR}\left(38.36^{\circ} \mathrm{C}\right), \mathrm{CHR}\left(38.11^{\circ} \mathrm{C}\right), \mathrm{OMR}\left(37.83^{\circ} \mathrm{C}\right)$, SB $\left(37.52^{\circ} \mathrm{C}\right)$ and OHR $\left(37.38^{\circ} \mathrm{C}\right)$ (Figure $\left.4 \mathrm{a}\right)$. The HI class in this study area is a railway station, featuring a large amount of metal materials and high SVF, combined with a massive energy consumption and high population density of commuters, making its LST higher than that of the others. The compact classes (CLR, CMR and CLR) have a higher LST than the open classes (OLR, OMR and OHR). Typically, the compact spatial forms have a higher building density, population density and impervious surface fraction, as well as a lower fraction of open space (e.g., green space and blue space) than open spatial forms, which is also presented in Table A1. Thus, the compact areas feature a higher anthropogenic heat release and solar radiation absorption than the open areas, causing heat accumulation in the compact areas and a higher LST.

In addition, low-rise spatial forms are more vulnerable to heat waves than high-rise spatial forms, and this trend is more significant in the compact classes (Figure 4a). Even though the CHR have higher building construction intensities than CLR, CLR are primarily low-rise buildings, featuring limited open space and a scattered building spatial form layout, which results in poor ventilation conditions. Thus, heat easily accumulates in this area, causing significant deterioration of the thermal environment. Furthermore, to provide adequate lighting and fire protection for tall buildings, high-rise urban spatial forms typically have a regular building layout and a substantial amount of open space, which not only accommodates ventilation, but can also effectively mitigates the urban heat island effect by providing a large amount of green space between high-rise buildings. In addition, due to sunlight angle limitations, shadows from tall buildings can greatly reduce the total amount of solar radiation reaching the ground surface, which results in a low LST. 

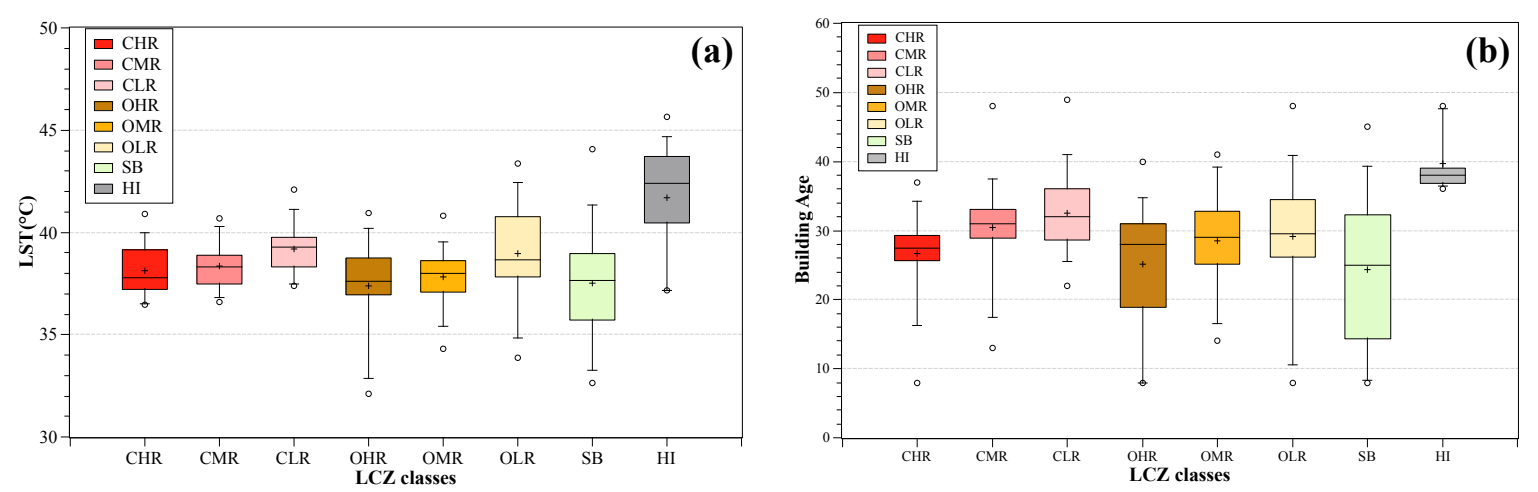

Figure 4. Boxplots of land surface temperature (LST) (a) and building age (BA) (b) in different LCZ classes. (The upper and lower bounds of the box plots indicate the $25^{\text {th }}$ and $75^{\text {th }}$ percentiles of the values, the whiskers represent the $5^{\text {th }}$ and $95^{\text {th }}$ percentiles, the cross depicts the mean value, the midlines represent the median value, and the upper and lower ellipses illustrate the maximum and minimum values, respectively.).

\subsection{Building Age of LCZ Classes}

The mean building age in decreasing order is as follows: HI (40), CLR (33), CMR (30), OLR (29), OMR (28), CHR (27), OHR (25), and SB (24) (Figure 4b). This is also consistent with the development history of cities.

The HI class in this study area includes the oldest railway station. The mean building age shows that there has been little change since the station was built and put into use, and the city may be developed from it and used it for early industrial transportation. In this fast-growing megacity, urban renewal and urban sprawl always occurred simultaneously in the past few years. In the eastern part of the study area, the power of the market economy pressures the old areas to be gradually renewed and transformed to newer development areas, with higher intensities for the unique central location, which led the urban spatial form be changed from low-rise to mid-rise and then high-rise, and thus the building age of them accordingly decreased as they changed from a low-rise to a mid-rise and then a high-rise urban spatial form. While in the western part, the transformation of urban space dominated by urban expansion and the terrain makes construction more difficult, more open spatial forms are provided. That is the reason why most open classes are younger than the compact classes. However, it should be noted that there has been no extra land for expansion in recent years in the study area, which forces some sites to be developed in a high-intensity way (open high-rise). Sparsely built classes are far away from the eastern center, located near rivers or mountain areas in the new developed area in the western part with small land (Figure 3a), and most of them are temporary buildings, thus, they are the youngest classes in the whole area.

\subsection{Housing Price of LCZ Classes}

The mean housing prices per square meter are (in descending order): CHR (2243 $\left.\$ / \mathrm{m}^{2}\right)$, OHR $\left(2150 \$ / \mathrm{m}^{2}\right)$, OLR $\left(2112 \$ / \mathrm{m}^{2}\right)$, SB $\left(2112 \$ / \mathrm{m}^{2}\right)$, CLR $\left(2021 \$ / \mathrm{m}^{2}\right)$, OMR $\left(1997 \$ / \mathrm{m}^{2}\right)$, CMR $\left(1963 \$ / \mathrm{m}^{2}\right)$ and HI $\left(1768 \$ / \mathrm{m}^{2}\right)$ (Figure 5a). The distribution of LCZ classes reveals that most CHR classes are located in the central area (Figure 3), where the premium effect of land price results in a higher housing price. While OHR, OLR and SB classes are far from the city center, most of those areas are near large green spaces or water bodies (Figure 3) and have a beautiful natural landscape, because it is usually developed for luxury residential housing, which also results in a higher housing price too. Other LCZ classes, such as CLR, OMR and CMR, have no obvious advantages in terms of location or beautiful landscapes and are mostly characterized by the same construction density. Thus, there is little difference in the mean housing price. HI classes have the lowest housing prices, as they are subjected to noise, waste water and air pollution, which have a significant negative impact on the surrounding environment, resulting in a significant "Not In My Back Yard" effect. 

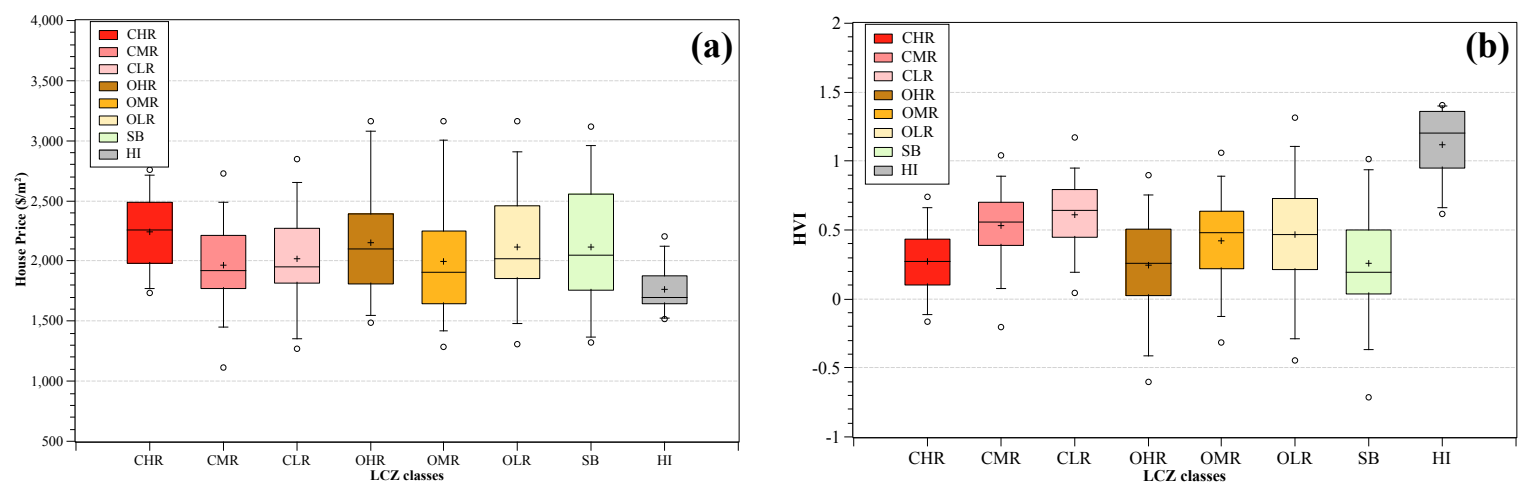

Figure 5. Boxplots of housing price (HP) (a) and heat vulnerability index (HVI) (b) in different LCZ classes.

\subsection{The Vulnerability of Different LCZ Classes}

After using the equal weight method to assess the heat vulnerability of different LCZs by LST, BA and HP, which represent heat exposure, sensitivity and adaptability, respectively, the mean heat vulnerability index values are (in descending order): HI (1.086), CLR (0.608), CMR (0.530), OLR (0.473), OMR (0.434), CHR (0.296), SB (0.266), and OHR (0.254) (Figure 5b). The HI class area is the most vulnerable in the city due to its severely thermal environments, poor infrastructure and poor economic conditions. Low-rise buildings are more vulnerable than mid-rise buildings and high-rise buildings, because most low-rise buildings are older than those in other classes and are situated in built environments and facility infrastructures that have a poor condition due to years of little maintenance. Moreover, since a larger proportion of the vulnerable population (e.g., elderly and low-income) live in low-rise buildings, the CLR classes constitute one of the most vulnerable areas in the city center during the extreme heat wave periods. CHR classes are also located in the central areas. The results, combining LST, BA and HP, reveal that CHR has a low thermal vulnerability for a better thermal environment, and residents living in these tall buildings tended to have better economic conditions and were younger than those in other LCZs. There are few differences in the thermal environment, building age and housing price between CMR, OLR and OMR classes, which results in a similar heat vulnerability index. Moreover, OHR classes have a low LST, young building age and high housing price. Thus, it has the lowest heat vulnerability index and its residents have a higher resistance to heat waves.

\section{Discussion}

\subsection{Reducing the Heat Vulnerability by Water Bodies and Green Spaces}

Water bodies and green spaces have significant positive effects on humans' health and well-being. In this study, the mean value of LST demonstrates that water bodies $\left(27.69^{\circ} \mathrm{C}\right)$ always have the lowest LST, which implies that blue spaces are effective factors in reducing the negative impact of heat waves and enhancing heat resilience. As Cai (2018) [43] pointed out in the same study area, the cooling effect of water bodies has a great impact on the relationship between urban form factors and LST, especially when the sample's distance to water bodies is less than $250 \mathrm{~m}$. Taking the HI classes as an example, in the heat vulnerability assessment, there is little difference in the housing price and building age between them, while there is great difference in the distribution of LST. The HI samples near water bodies have a lower LST, and the samples far from the water bodies have a higher LST, which results in a big HVI value range and the HI samples near water bodies have a lower HVI value (Figure $6 \mathrm{~h}$ ). Blue spaces not only have a substantial impact on the urban thermal environment [43], but also positively affect socio-economic conditions, such as neighboring housing prices [55,56]. As Qiang (2019) [55] and Luttik (2000) [56] pointed out, wealthier residents possess a higher share of ocean 
visibility. We have found a similar influence in this study area, that is, most of the LCZ classes near water bodies have a higher housing price (Figure 1d).

To further explore the extent of the influence of water bodies on the surrounding area, we analyzed the correlation coefficients between HVI and LCZ classes in terms of the distance from water bodies (DIST). The results showed that there is a significant positive relationship between HVI and LCZ classes in terms of the distance from water bodies (DIST) $\left(0.278^{* *}, p<0.001\right)$, that is, the further away from water bodies, the higher the HVI. While the optimal cubic fitting functions (HVI $=2.72 \mathrm{DIST}^{3} 10^{-10}$ $\left.-1.06 \mathrm{DIST}^{2} 10^{-6}+2.16 \mathrm{DIST} 10^{-3}+0.06, \mathrm{R}^{2}=0.138\right)$ indicate that the influence of water bodies has a maximum distance $(823 \mathrm{~m}$, Figure $6 \mathrm{i})$.

Lots of studies also noted that green spaces can mitigate the heat island effect and benefit human health [57], and the socio-economic improvement effect is more significant around large green urban parks [58]. We have not found a significant influence of green spaces on heat vulnerability in this study, since there are few dense tree classes or scattered tree classes, and most of those areas are difficult to reach due to the large fluctuations of terrain. However, the role of green spaces in mitigating heat vulnerability should not be ignored, since green spaces have an obvious lower mean LST $\left(34.95^{\circ} \mathrm{C}\right)$ compared to other LCZ classes.
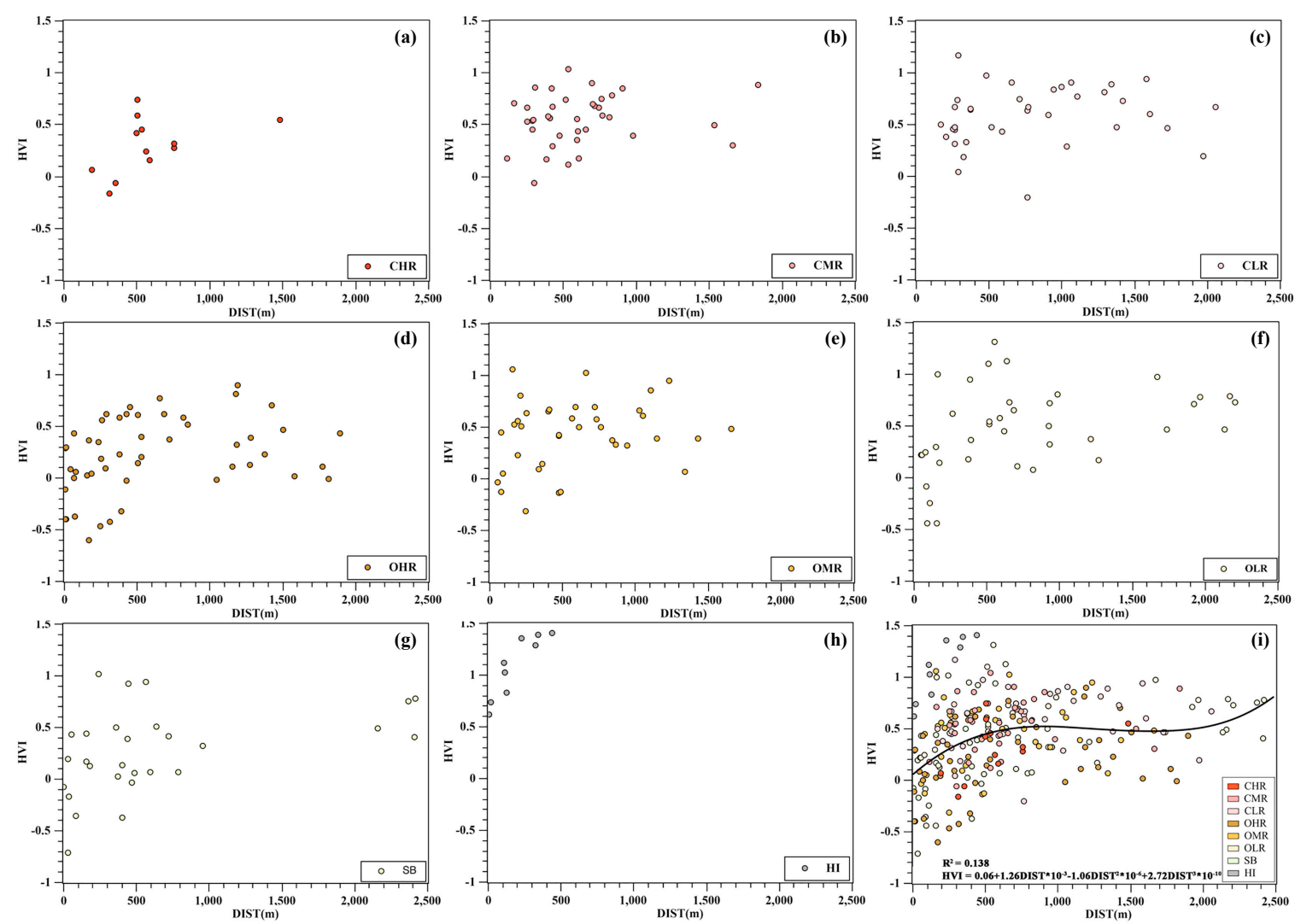

Figure 6. Scatter plot of HVI and LCZ classes ((a) CHR classes; (b) CMR classes; (c) CLR classes; (d) OHR classes; (e) OMR classes; (f) OLR classes; (g) SB classes; (h) HI classes; (i) all LCZ sample classes) in terms of the distance from water bodies (DIST).

\subsection{Limitations and Future Work}

This paper primarily assessed heat vulnerability from a built environment perspective, and its consideration regarding the residents' socio-economic conditions (e.g., income, age and gender) could be further enriched. We used house age and housing price to represent the related socio-economic conditions, but this index may only be applied in rapidly developing Chinese mega-cities at the microscale, such as the old areas located in the city center. In future work, it will be necessary to 
combine more socio-economic factors with the LCZ scheme at the mesoscale to assess heat vulnerability characteristics and compare the differences with other types of cities.

What is more, this paper used the equal weight overlay method and normalized data to calculate the heat vulnerability index. Sometimes, this interaction could be nonlinear, but until now, we still have little knowledge about the correlations. Thus, it would be useful to explore and identify the quantitative relationship between heat exposure, sensitivity, adaptability and heat vulnerability index in the future, as well as to find out which factors have the greatest impact on human health.

\section{Conclusions}

Using a local climate zone classification scheme, combined with land surface temperature (LST), building age (BA) and housing price (HP), and the normalized values of which represent heat exposure, sensitivity, and adaptability, respectively, this study assesses the heat vulnerabilities (HVI) from a built environment perspective for the old areas of a Chinese megacity. The results showed that the distribution of LCZ classes presents a typical circle-layer distribution pattern from the city center to the suburbs. The mean LST, BA and HP vary in each LCZ class. The HI classes are the most vulnerable areas, with the highest exposure to heat waves, the oldest building age, and the lowest housing price. Thus, the people who work in HI class areas or live in surrounding areas should be more considered in urban planning. Compared to open class areas (open high-rise, open mid-rise, open low-rise), compact class areas (compact high-rise, compact mid-rise, compact low-rise) are more vulnerable to heat waves, with a dense population and few green spaces. Interestingly, low-rise classes are more vulnerable than mid-rise and high-rise classes in this case due to their poor thermal environments and higher proportion of vulnerable populations. This study also found that water bodies play an important role in mitigating the heat island effect, increasing the housing price of surrounding areas, and improving residents' resilience to heat waves.

This paper tries to use the LCZ classified units instead of traditional administrative units as the spatial scale for heat vulnerability assessments and related calculation, with the highly detailed spatial resolution of LCZ classes and HVIs, urban planners and designers can clearly discover the distribution of different land uses/covers, urban spatial forms and heat vulnerabilities on the micro-scale, then reveal the correlations between the built environment, local climate and human health. Together, this will be greatly beneficial for them to formulate targeted strategies to improve the urban built environment and reduce heat risks.

Author Contributions: Conceptualization, Z.C. and Y.T.; Methodology, Z.C., Y.T. and K.C.; Software, Z.C.; Validation, K.C., Y.T. and G.H.; Formal analysis, Z.C.; Data curation, Z.C.; Writing-original draft preparation, Z.C.; Writing-review and editing, Y.T.; Supervision, Y.T.; Project administration, Y.T. and G.H.; Funding acquisition, Y.T. and G.H. All authors have read and approved the final manuscript.

Funding: This study was supported by the National Key Research and Development Program of China (Grant No. 2018YFC0704600), National Science Foundation of China (Grant No. 51408332 and No. 51778077), and Tsinghua University Initiative Scientific Research Program (Grant No. 2019Z02HKU and No. 2015Z09005).

Acknowledgments: We thank the anonymous reviewers for their constructive comments and suggestions as well as editors in relation to the manuscript.

Conflicts of Interest: The authors declare no conflict of interest. 


\section{Appendix A}

Table A1. Values of different index properties for LCZ classes.

\begin{tabular}{|c|c|c|c|c|c|c|c|c|c|c|}
\hline LCZ & $\begin{array}{l}\text { Sky View } \\
\text { Factor }\end{array}$ & $\begin{array}{l}\text { Aspect } \\
\text { Ratio }\end{array}$ & $\begin{array}{l}\text { Building Surface } \\
\text { Fraction (\%) }\end{array}$ & $\begin{array}{l}\text { Impervious Surface } \\
\text { Fraction (\%) }\end{array}$ & $\begin{array}{l}\text { Pervious Surface } \\
\text { Fraction (\%) }\end{array}$ & $\begin{array}{l}\text { Height of Roughness } \\
\text { Elements }(\mathrm{m})\end{array}$ & $\begin{array}{c}\text { Terrain } \\
\text { Roughness Class }\end{array}$ & $\begin{array}{l}\text { Surface Admittance } \\
\left(\mathrm{J} \mathrm{m}^{-2} \mathrm{~s}^{-1 / 2} \mathrm{~K}^{-1}\right)\end{array}$ & $\begin{array}{l}\text { Surface } \\
\text { Albedo }\end{array}$ & $\begin{array}{c}\text { Anthropogenic Heat } \\
\text { Output }\left(\mathrm{W} \mathrm{m}^{-2}\right)\end{array}$ \\
\hline $\begin{array}{c}\text { LCZ1 } 1 \\
\text { Compact High-Rise (CHR) }\end{array}$ & $0.2-0.4$ & $>2$ & $40-60$ & $40-60$ & $<10$ & $>25$ & 8 & 1500-1800 & $0.10-0.20$ & 50-300 \\
\hline $\begin{array}{c}\text { LCZ } 2 \\
\text { Compact Mid-rise } \\
\text { (CMR) }\end{array}$ & $0.3-0.6$ & $0.75-2$ & $40-70$ & $30-50$ & $<20$ & $10-25$ & 6-7 & $1500-2200$ & $0.10-0.20$ & $<75$ \\
\hline $\begin{array}{c}\text { LCZ } 3 \\
\text { Compact Low-rise (CLR) }\end{array}$ & $0.2-0.6$ & $0.75-1.5$ & $40-70$ & $20-50$ & $<30$ & $3-10$ & 6 & $1200-1800$ & $0.10-0.20$ & $<75$ \\
\hline $\begin{array}{c}\text { LCZ } 4 \\
\text { Open High-rise (OHR) }\end{array}$ & $0.5-0.7$ & $0.75-1.25$ & $20-40$ & $30-40$ & $30-40$ & $>25$ & $7-8$ & $1400-1800$ & $0.12-0.25$ & $<50$ \\
\hline $\begin{array}{c}\text { LCZ } 5 \\
\text { Open Mid-rise (OMR) }\end{array}$ & $0.5-0.8$ & $0.3-0.75$ & $20-40$ & $30-50$ & $20-40$ & $10-25$ & $5-6$ & $1400-2000$ & $0.12-0.25$ & $<25$ \\
\hline $\begin{array}{c}\text { LCZ } 6 \\
\text { Open Low-rise (OLR) }\end{array}$ & $0.6-0.9$ & $0.3-0.75$ & $20-40$ & $20-50$ & $30-60$ & $3-10$ & $5-6$ & $1200-1800$ & $0.12-0.25$ & $<25$ \\
\hline $\begin{array}{c}\text { LCZ 7 } \\
\text { Lightweight Low-rise } \\
\end{array}$ & $0.2-0.5$ & $1-2$ & $60-90$ & $<20$ & $<30$ & $2-4$ & $4-5$ & 800-1500 & $0.15-0.35$ & $<35$ \\
\hline $\begin{array}{c}\text { LCZ } 8 \\
\text { Large Low-rise } \\
\end{array}$ & $>0.7$ & $0.1-0.3$ & $10-20$ & $40-50$ & $<20$ & $3-10$ & 5 & $1200-1800$ & $0.15-0.25$ & $<50$ \\
\hline $\begin{array}{c}\text { LCZ 9 } \\
\text { Sparsely Built (SB) }\end{array}$ & $>0.8$ & $0.1-0.25$ & $20-30$ & $<20$ & $60-80$ & $3-10$ & $5-6$ & 1000-1800 & $0.12-0.25$ & $<10$ \\
\hline LCZ 10 Heavy Industry (HI) & $0.6-0.9$ & $0.2-0.5$ & $<10$ & $20-40$ & $40-50$ & 5-15 & 5-6 & $1000-2500$ & $0.12-0.20$ & 0 \\
\hline $\begin{array}{c}\text { LCZ A } \\
\text { Dense Trees }\end{array}$ & $<0.4$ & $>1$ & $<10$ & $<10$ & $>90$ & 3-30 & 8 & - & $0.10-0.20$ & 0 \\
\hline $\begin{array}{c}\text { LCZ B } \\
\text { Scattered Trees }\end{array}$ & $0.5-0.8$ & $0.25-0.75$ & $<10$ & $<10$ & $>90$ & 3-15 & $5-6$ & $700-1500$ & $0.15-0.25$ & 0 \\
\hline $\begin{array}{c}\text { Lcz C } \\
\text { Bush, Scrub }\end{array}$ & $0.7-0.9$ & $0.25-1.0$ & $<10$ & $<10$ & $>90$ & $<2$ & $4-5$ & $1200-1600$ & $0.15-0.25$ & 0 \\
\hline $\begin{array}{c}\text { LCZ D } \\
\text { Low Plants }\end{array}$ & $>0.9$ & $<0.1$ & $<10$ & $<10$ & $>90$ & $<1$ & $3-4$ & $1200-2500$ & $0.15-0.30$ & 0 \\
\hline $\begin{array}{c}\text { LCZ E } \\
\text { Bare Rock or Paved }\end{array}$ & $>0.9$ & $<0.1$ & $<10$ & $>90$ & $<10$ & $<0.25$ & $1-2$ & $600-1400$ & $0.20-0.35$ & 0 \\
\hline $\begin{array}{c}\text { LCZ F } \\
\text { Bare Soil or Sand }\end{array}$ & $>0.9$ & $<0.1$ & $<10$ & $<10$ & $>90$ & $<0.25$ & $1-2$ & $600-1400$ & $0.20-0.35$ & 0 \\
\hline $\begin{array}{l}\text { LCZ G } \\
\text { Water }\end{array}$ & $>0.9$ & $<0.1$ & $<10$ & $<10$ & $>90$ & - & 1 & 1500 & $0.02-0.10$ & 0 \\
\hline
\end{tabular}




\section{References}

1. Sailor, D.J.; Fan, H. Modeling the diurnal variability of effective albedo for cities. Atmos. Environ. 2002, 36, 713-725. [CrossRef]

2. Kalisa, E.; Fadlallah, S.; Amani, M.; Nahayo, L.; Habiyaremye, G. Temperature and air pollution relationship during heatwaves in Birmingham, UK. Sustain. Cities Soc. 2018, 43, 111-120. [CrossRef]

3. Mayrhuber, E.A.S.; Dückers, M.L.; Wallner, P.; Arnberger, A.; Allex, B.; Wiesböck, L.; Kutalek, R. Vulnerability to heatwaves and implications for public health interventions-A scoping review. Environ. Res. 2018, 166, 42-54. [CrossRef] [PubMed]

4. Huang, J.; Zhou, C.; Zhuo, Y.; Xu, L.; Jiang, Y. Outdoor thermal environments and activities in open space: an experiment study in humid subtropical climates. Build. Environ. 2016, 103, 238-249. [CrossRef]

5. Dye, C. Health and urban living. Science 2008, 319, 766-769. [CrossRef]

6. Khalaj, B.; Lloyd, G.; Sheppeard, V.; Dear, K. The health impacts of heat waves in five regions of New South Wales, Australia: A case-only analysis. Int. Arch. Occup. Environ. Health 2010, 83, 833-842. [CrossRef] [PubMed]

7. CDC. Asthma in the US Growing Every Year. CDC Vital Signs; 2011. Available online: http://www.cdc. gov/vitalsigns/asthma/ (accessed on 15 January 2019).

8. Yeganeh, A.J.; Reichard, G.; McCoy, A.P.; Bulbul, T.; Jazizadeh, F. Correlation of ambient air temperature and cognitive performance: A systematic review and meta-analysis. Build. Environ. 2018. [CrossRef]

9. Ostfeld, R.S.; Brunner, J.L. Climate change and Ixodes tick-borne diseases of humans. Philos. Trans. R. Soc. B: Biol. Sci. 2015, 370, 20140051. [CrossRef] [PubMed]

10. Wu, X.; Lu, Y.; Zhou, S.; Chen, L.; Xu, B. Impact of climate change on human infectious diseases: Empirical evidence and human adaptation. Environ. Int. 2016, 86, 14-23. [CrossRef]

11. Schinasi, L.H.; Benmarhnia, T.; de Roos, A.J. Modification of the association between high ambient temperature and health by urban microclimate indicators: A systematic review and meta-analysis. Environ. Res. 2018, 161, 168-180. [CrossRef]

12. Rovers, V.; Bosch, P.R.; Albers, R. Final Report Climate Proof Cities 2010-2014. KFC 129/2014. 2014. Available online: http:/ / edepot.wur.nl/351021 (accessed on 15 January 2019).

13. Robine, J.M.; Cheung, S.L.K.; Le Roy, S.; van Oyen, H.; Griffiths, C.; Michel, J.P.; Herrmann, F.R. Death toll exceeded 70,000 in Europe during the summer of 2003. Comptes Rendus Biol. 2008, 331, 171-178. [CrossRef] [PubMed]

14. Center for Disease Control and Prevention (CDC) US. Climate Change and Extreme Heat Events; Center for Disease Control and Prevention: Atlanta, GA, USA, 2013.

15. IPCC. Summary for policymakers. In Climate Change 2014, Mitigation of Climate Change. Contribution of Working Group III to the Fifth Assessment Report of the Intergovernmental Panel on Climate Change; In, O., Edenhofer, R., Pichs-Madruga, Y., Sokona, E., Farahani, S., Kadner, K., Seyboth, A., Adler, I., Baum, S., Brunner, P., et al., Eds.; Cambridge University Press: Cambridge, UK, 2014; pp. 1-33.

16. Leal Filho, W.; Icaza, L.E.; Neht, A.; Klavins, M.; Morgan, E.A. Coping with the impacts of urban heat islands. A literature based study on understanding urban heat vulnerability and the need for resilience in cities in a global climate change context. J. Clean. Prod. 2018, 171, 1140-1149. [CrossRef]

17. Füssel, H.M. Vulnerability: A generally applicable conceptual framework for climate change research. Glob. Environ. Change 2007, 17, 155-167. [CrossRef]

18. Madrigano, J.; Ito, K.; Johnson, S.; Kinney, P.L.; Matte, T. A case-only study of vulnerability to heat wave-related mortality in New York City (2000-2011). Environ. Health Perspect. 2015, 123, 672-678. [CrossRef] [PubMed]

19. Inostroza, L.; Palme, M.; de la Barrera, F. A heat vulnerability index: spatial patterns of exposure, sensitivity and adaptive capacity for Santiago de Chile. PloS ONE 2016, 11, e0162464. [CrossRef] [PubMed]

20. van der Hoeven, F.; Wandl, A. Amsterwarm: Mapping the landuse, health and energy-efficiency implications of the Amsterdam urban heat island. Build. Serv. Eng. Res. Technol. 2015, 36, 67-88. [CrossRef]

21. Wolf, T.; McGregor, G. The development of a heat wave vulnerability index for London, United Kingdom. Weather Clim. Extremes 2013, 1, 59-68. [CrossRef]

22. Birkmann, J. Measuring Vulnerability to Natural Hazards: Towards Disaster Resilient Societies; No. Sirsi i9789280811353; TERI Press: New Dehli, India, 2006. 
23. Ma, M.; Cai, W.; Cai, W.; Dong, L. Whether carbon intensity in the commercial building sector decouples from economic development in the service industry? Empirical evidence from the top five urban agglomerations in China. Journal of Cleaner Production. 2019, 222, 193-205. [CrossRef]

24. Walton, Z.L.; Poudyal, N.C.; Hepinstall-Cymerman, J.; Gaither, C.J.; Boley, B.B. Exploring the role of forest resources in reducing community vulnerability to the heat effects of climate change. For. Policy Econ. 2016, 71, 94-102. [CrossRef]

25. Dong, W.; Liu, Z.; Zhang, L.; Tang, Q.; Liao, H.; Li, X.E. Assessing heat health risk for sustainability in Beijing's urban heat island. Sustainability 2014, 6, 7334-7357. [CrossRef]

26. Stewart, I.D.; Oke, T.R. Local climate zones for urban temperature studies. Bull. Am. Meteorol. Soc. 2012, 93, 1879-1900. [CrossRef]

27. Yang, X.; Yao, L.; Jin, T.; Peng, L.L.; Jiang, Z.; Hu, Z.; Ye, Y. Assessing the thermal behavior of different local climate zones in the Nanjing metropolis, China. Build. Environ. 2018, 137, 171-184. [CrossRef]

28. Mushore, T.D.; Dube, T.; Manjowe, M.; Gumindoga, W.; Chemura, A.; Rousta, I.; Mutanga, O. Remotely sensed retrieval of local climate zones and their linkages to land surface temperature in Harare metropolitan city, Zimbabwe. Urban Clim. 2019, 27, 259-271. [CrossRef]

29. Cai, Z.; Han, G. F. Assessing land surface temperature in the mountain city with different urban spatial form based on local climate zone scheme. J. Mt. Res. 2018, 36, 617-627. (In Chinese)

30. Brousse, O.; Georganos, S.; Demuzere, M.; Vanhuysse, S.; Wouters, H.; Wolff, E.; Dujardin, S. using local climate zones in Sub-Saharan Africa to tackle urban health issues. Urban Clim. 2019, 27, 227-242. [CrossRef]

31. Verdonck, M.L.; Demuzere, M.; Hooyberghs, H.; Beck, C.; Cyrys, J.; Schneider, A.; Van Coillie, F. The potential of local climate zones maps as a heat stress assessment tool, supported by simulated air temperature data. Landsc. Urban Plann. 2018, 178, 183-197. [CrossRef]

32. Shi, Y.; Lau, K.K.L.; Ren, C.; Ng, E. Evaluating the local climate zone classification in high-density heterogeneous urban environment using mobile measurement. Urban Clim. 2018, 25, 167-186. [CrossRef]

33. Demuzere, M.; Bechtel, B.; Mills, G. Global transferability of local climate zone models. Urban Clim. 2019, 27, 46-63. [CrossRef]

34. Li, C.; Yu, C.W. Mitigation of urban heat development by cool island effect of green space and water body. In Proceedings of the 8th International Symposium on Heating, Ventilation and Air Conditioning; Springer: Berlin, Germany, 2014; pp. 551-561.

35. Han, G.F.; Cai, Z.; Xie, Y.S.; Zeng, W. Correlation between urban construction and urban heat island: A case study in Kaizhou District, Chongqing. J. Civ. Arch. Env. Eng. 2016, 38, 138-147. (In Chinese) [CrossRef]

36. Chun, B.; Guldmann, J.M. Spatial statistical analysis and simulation of the urban heat island in high-density central cities. Landsc. Urban Plan. 2014, 125, 76-88. [CrossRef]

37. Song, J.; Du, S.; Feng, X.; Guo, L. The relationships between landscape compositions and land surface temperature: Quantifying their resolution sensitivity with spatial regression models. Landsc. Urban Plann. 2014, 123, 145-157. [CrossRef]

38. Masoudi, M.; Tan, P.Y. Multi-year comparison of the effects of spatial pattern of urban green spaces on urban land surface temperature. Landsc. Urban Plan. 2019, 184, 44-58. [CrossRef]

39. Klok, L.; Zwart, S.; Verhagen, H.; Mauri, E. The surface heat island of Rotterdam and its relationship with urban surface characteristics. Resour. Conserv. Recycl. 2012, 64, 23-29. [CrossRef]

40. Nichol, J.E.; Fung, W.Y.; Lam, K.S.; Wong, M.S. Urban heat island diagnosis using ASTER satellite images and 'in situ' air temperature. Atmos. Res. 2009, 94, 276-284. [CrossRef]

41. Schwarz, N.; Schlink, U.; Franck, U.; Großmann, K. Relationship of land surface and air temperatures and its implications for quantifying urban heat island indicators-An application for the city of Leipzig (Germany). Ecol. Indic. 2012, 18, 693-704. [CrossRef]

42. Sheng, L.; Tang, X.; You, H.; Gu, Q.; Hu, H. Comparison of the urban heat island intensity quantified by using air temperature and Landsat land surface temperature in Hangzhou, China. Ecol. Indic. 2017, 72, 738-746. [CrossRef]

43. Cai, Z.; Han, G.; Chen, M. Do water bodies play an important role in the relationship between urban form and land surface temperature? Sustain. Cities Soc. 2018, 39, 487-498. [CrossRef]

44. Zhou, S.; Xie, M.; Kwan, M.P. Ageing in place and ageing with migration in the transitional context of urban China: A case study of ageing communities in Guangzhou. Habitat Int. 2015, 49, 177-186. [CrossRef]

45. Scott, P. Urban population structure: an Australian case study. Geographer 1971, 18, 1-16. 
46. Waddicor, D.A.; Fuentes, E.; Sisó, L.; Salom, J.; Favre, B.; Jiménez, C.; Azar, M. Climate change and building ageing impact on building energy performance and mitigation measures application: A case study in Turin, northern Italy. Build. Environ. 2016, 102, 13-25. [CrossRef]

47. Atalay, K.; Edwards, R.; Liu, B.Y. Effects of house prices on health: New evidence from Australia. Soc. Sci. Med. 2017, 192, 36-48. [CrossRef] [PubMed]

48. Stewart, I.D.; Oke, T.R.; Krayenhoff, E.S. Evaluation of the 'local climate zone'scheme using temperature observations and model simulations. Int. J. Climatol. 2014, 34, 1062-1080. [CrossRef]

49. Oke, T.R. Canyon geometry and the nocturnal urban heat island: comparison of scale model and field observations. J. Climatol. 1981, 1, 237-254. [CrossRef]

50. Norton, B.A.; Coutts, A.M.; Livesley, S.J.; Harris, R.J.; Hunter, A.M.; Williams, N.S. Planning for cooler cities: A framework to prioritise green infrastructure to mitigate high temperatures in urban landscapes. Landsc. Urban Plan. 2015, 134, 127-138. [CrossRef]

51. Depietri, Y.; Welle, T.; Renaud, F.G. Social vulnerability assessment of the Cologne urban area (Germany) to heat waves: Links to ecosystem services. Int. J. Disaster Risk Reduct. 2013, 6, 98-117. [CrossRef]

52. Weber, S.; Sadoff, N.; Zell, E.; de Sherbinin, A. Policy-relevant indicators for mapping the vulnerability of urban populations to extreme heat events: A case study of Philadelphia. Appl. Geograph. 2015, 63, 231-243. [CrossRef]

53. Zhu, Q.; Liu, T.; Lin, H.; Xiao, J.; Luo, Y.; Zeng, W.; Du, Y. The spatial distribution of health vulnerability to heat waves in Guangdong Province, China. Glob. Health Action 2014, 7, 25051. [CrossRef] [PubMed]

54. Rinner, C.; Patychuk, D.; Bassil, K.; Nasr, S.; Gower, S.; Campbell, M. The role of maps in neighborhood-level heat vulnerability assessment for the city of Toronto. Cartogr. Geogr. Inf. Sci. 2010, 37, 31-44. [CrossRef]

55. Qiang, Y.; Shen, S.; Chen, Q. Visibility analysis of oceanic blue space using digital elevation models. Landsc. Urban Plan. 2019, 181, 92-102. [CrossRef]

56. Luttik, J. The value of trees, water and open space as reflected by house prices in the Netherlands. Landsc. Urban Plan. 2000, 48, 161-167. [CrossRef]

57. Coccolo, S.; Pearlmutter, D.; Kaempf, J.; Scartezzini, J.L. Thermal comfort maps to estimate the impact of urban greening on the outdoor human comfort. Urban For. Urban Green. 2018, 35, 91-105. [CrossRef]

58. Kim, H.S.; Lee, G.E.; Lee, J.S.; Choi, Y. Understanding the local impact of urban park plans and park typology on housing price: A case study of the Busan metropolitan region, Korea. Landsc. Urban Plan. 2019, 184, 1-11. [CrossRef]

(C) 2019 by the authors. Licensee MDPI, Basel, Switzerland. This article is an open access article distributed under the terms and conditions of the Creative Commons Attribution (CC BY) license (http:/ / creativecommons.org/licenses/by/4.0/). 